\begin{abstract}
Time series of depth data, obtained for 6 oceanic whitetip sharks (Carcharhinus longimanus) tagged with pop-up satellite archival tags, were analyzed in detail. The aim was to improve our knowledge of the vertical behavior of this species. Individuals were tagged in the Atlantic Ocean $(n=5)$ and Indian Ocean $(n=1)$ between 2011 and 2012. Deployment periods for these tags varied from 100 to $178 \mathrm{~d}$. The sharks spent most of their time in the mixed layer, displaying the typical behavior of an epipelagic species. However, analyses revealed complex vertical movement patterns, including marked diel changes that reflect 3 different types of behavior. Results of the generalized additive models indicate that vertical movements were strongly correlated with variations in the depth of the mixed layer. A correlation between vertical movements and sea-surface temperature (SST) was also observed. When SST was above average, oceanic whitetip sharks increased their vertical amplitude, disregarding the reduction of the mixed layer. Thermoregulation likely allows this type of vertical movement.
\end{abstract}

Manuscript submitted 7 September 2016. Manuscript accepted 15 May 2017.

Fish. Bull. 115:380-395 (2017).

Online publication date: 14 June 2017. doi: 10.7755/FB.115.3.8

The views and opinions expressed or implied in this article are those of the author (or authors) and do not necessarily reflect the position of the National Marine Fisheries Service, NOAA.

\title{
Fine-scale vertical movements of oceanic whitetip sharks (Carcharhinus longimanus)
}

\author{
Mariana Tolotti (contact author) 1,2 \\ Robert Bauer ${ }^{1}$ \\ Fabien Forget ${ }^{1}$ \\ Pascal Bach ${ }^{1}$ \\ Laurent Dagorn' \\ Paulo Travassos $^{3}$ \\ Email address for contact author: mariana.travassos@ird.fr \\ 1 Unité Mixte de Recherche (UMR) Marine Biodiversity, Exploitation, and Conservation \\ (MARBEC) \\ Institut de Recherche pour le Développement \\ Avenue Jean Monnet CS 30171 \\ 34203 Sète Cedex, France \\ 2 Departamento de Oceanografia \\ Universidade Federal de Pernambuco \\ Avenida Professor Moraes Rego, 1235-Cidade Universitária \\ 50670-901 Recife, Brazil \\ 3 Departamento de Pesca e Aquicultura \\ Universidade Federal Rural de Pernambuco \\ Rua Dom Manoel de Medeiros s/n-Dois Irmãos \\ 52171-900 Recife, Brazil
}

The oceanic whitetip shark (Carcharhinus longimanus) is a pelagic predator threatened across the tropical oceans of the world (Bonfil et al., 2008). This species is a common bycatch of pelagic fisheries that target tuna (Thunnus spp.), swordfish (Xiphias gladius), and other tuna-like species (Beerkircher et al., 2002; Hall and Roman, 2013; Gallagher et al., 2014; Frédou et al., 2015; Oliver et al., 2015). The oceanic whitetip shark acquired its status of vulnerable globally and critically endangered in the northwest and western central Atlantic Ocean on the IUCN Red List of Threatened Species because of the increasing fishing pressure throughout its range and because of a lack of information regarding its biology and ecology (Baum et al., 2015). As a precautionary approach, a series of management measures that banned the landing, storing, and selling of oceanic whitetip sharks were implemented recently by management organizations of all regional tuna fisheries (Tolotti et al., 2015a). To date, this species is the only pelagic shark protected in the Atlantic, Pacific, and Indian oceans. The Convention on International Trade in Endangered Species of Wild Fauna and Flora has also included the oceanic whitetip shark in its Appendix II (CoP16 Prop. 42), which includes species for which trade must be closely controlled.

The lack of information regarding the biology and ecology of the oceanic whitetip shark is partly due to it being captured as bycatch-a situation that has historically resulted in few incentives for research and conservation (Barker and Schluessel, 2005). In light of the ocean-wide population declines observed for this species and because of the increasing interest in the conservation of bycatch species, 
the scientific community recently has undertaken significant research to fill these wide gaps in scientific information. These studies include work on age, growth, and reproductive biology (Tambourgi et al., 2013; Joung et al., 2016), feeding (Madigan et al., 2015), genetics (Camargo et al., 2016; Li et al., 2016), fisheries (Rice and Harley; ${ }^{1}$ Tolotti et al., 2013; Piovano and Gilman, 2016), and movement patterns and behavior (Musyl et al., 2011; Howey-Jordan et al., 2013; Tolotti et al., 2015b; Howey et al., 2016).

Data from satellite archival tags, together with fishery-dependent data, revealed valuable information concerning horizontal movements, depth preferences, and temperature ranges of the oceanic whitetip shark. Previous studies have shown that this wide-ranging species has a high degree of site fidelity and exhibits philopatric behavior (Howey-Jordan et al., 2013; Madigan et al., 2015; Tolotti et al., 2015b). They also have documented the epipelagic nature of this species and its high degree of vulnerability to open-ocean fisheries. These findings are new and have conservation applications, but several aspects of the behavior of this shark still need to be addressed. Detailed information on vertical movements within the epipelagic environment still need to be studied; most of the published research concerning this species has not explored vertical movements, and only general summaries have been provided.

Within the general framework of ecosystem-based fisheries management, it is essential to improve our knowledge of bycatch species (particularly for threatened species), including our knowledge of their behavior and vertical movement patterns (Pikitch et al., 2004; Garcia and Cochrane, 2005). The aim of this study was to analyze the vertical movements of the oceanic whitetip shark in order to extend our knowledge beyond the existing knowledge that this is an epipelagic species. The main objectives were 1) to investigate diel patterns and behavior types and 2) to analyze the influence of environmental factors on the vertical behavior of this shark.

\section{Materials and methods}

Time series of depth data for 6 oceanic whitetip sharks were analyzed. All data were obtained from pop-up satellite archival tags deployed in the Atlantic Ocean $(n=5)$ and Indian Ocean $(n=1)$ in 2011 and 2012 (Table 1). Deployment periods varied from 100 to $178 \mathrm{~d}$. Summarized results, based on the data from the 5 tags deployed in the Atlantic Ocean, were previously presented in Tolotti et al. (2015b). The sharks in the Atlantic Ocean were tagged close to the equator on the western side of the Atlantic Ocean during commercial longline operations. The sharks were brought onboard

\footnotetext{
${ }^{1}$ Rice, J., and S. Harley. 2012. Stock assessment of oceanic whitetip sharks in the western and central Pacific Ocean. West. Cent. Pacific Fish. Comm. WCPFC-SC8-2012/SAWP-06, rev. 1, 53 p. [Available from website.]
}

for the tagging procedure, and tags were attached at the base of the first dorsal fin with a loop of polyamide monofilament. In addition to the vertical movements reported here, horizontal movements were observed for the sharks. After tagging, all individuals made extensive horizontal movements but remained mostly in the equatorial zone (Tolotti et al., 2015b). Only 1 shark migrated south. The shark tagged in the Indian Ocean was caught with a hand line during a research cruise in the Mozambique Channel. For the tagging procedure, this shark was brought on board and placed in a tagging cradle. The tag was attached intramuscularly under the first dorsal fin with a stainless steel tether and large Wilton anchors (Wildlife Computers Inc., ${ }^{2}$ Redmond, WA). From its tagging location in the Mozambique Channel, this individual migrated north, following the African coast to Somalia. The estimated tracks of all 6 tagged individuals are provided in Supplementary Figure 1.

\section{Data description}

Pop-up satellite archival tags typically record the ambient depth (pressure), water temperature, and light level at a high temporal resolution (for our study, the resolution was $10 \mathrm{~s}$ ). This information is then used to generate different data products that are transmitted by satellite after the tags detach from the animal. Transmitted data products will depend on tag model and user-defined settings. Two models of pop-up satellite archival tags, manufactured by Wildlife Computers Inc., were used in this study, 5 MiniPATs and 1 PATMk10. The MiniPATs were programmed to transmit depth data with a resolution of $5 \mathrm{~min}$. The PAT-Mk10 does not transmit data as a time series, only as an aggregated summary of its records. However, this latter tag was physically recovered from Crystal Beach, Texas, after drifting at sea for about 1 year after its release from the shark. The recovery of this tag allowed the download of the complete depth and temperature time series with a $10-$ s resolution. The MiniPATs were not recovered. Although MiniPATs were not programmed to transmit temperature time-series data, other data produced and transmitted by the tags provided information on the surrounding environment. These products included a daily analysis of the surface mixed layer and sea-surface temperature (SST), as well as a summary of temperature at depth profiles. These data were also available from the recovered PAT-Mk10.

\section{Data analysis}

Vertical movement patterns The periods of the day were classified according to local times of sunrise and sunset, by following the procedure described in Tolotti et al. $(2015 b)$. In summary, the local times were based

\footnotetext{
${ }^{2}$ Mention of trade names or commercial companies is for identification purposes only and does not imply endorsement by the National Marine Fisheries Service, NOAA.
} 


\section{Table 1}

Details from the electronic tagging of oceanic whitetip sharks (Carcharhinus longimanus) in the Atlantic and Indian oceans between 2011 and 2012: identification (ID) code, total length (TL), sex, location, model of pop-up satellite archival tag used, the period that tags were set to record data (programmed). Tagging: date when a fish was tagged, and location of tagging (latitude [lat] and longitude [long]). Pop-up: date when a tag popped up (was released), location of released tag, and the number of days that the tag had remained on the fish.

\begin{tabular}{|c|c|c|c|c|c|c|c|c|c|c|c|c|}
\hline \multirow[b]{2}{*}{ ID } & \multirow[b]{2}{*}{$\mathrm{TL}(\mathrm{cm})$} & \multirow[b]{2}{*}{ Sex } & \multirow[b]{2}{*}{ Ocean } & \multirow[b]{2}{*}{ Tag } & \multirow[b]{2}{*}{ Programmed } & \multicolumn{3}{|c|}{ Tagging } & \multicolumn{3}{|c|}{ Pop-up } & \multirow[b]{2}{*}{ Duration } \\
\hline & & & & & & Date & Lat. & Long. & Date & Lat & Long & \\
\hline AOCS3 & 167 & M & Atlan & PAT-Mk10*** & $* 180 \mathrm{~d}$ & $16 / 01 / 2011$ & -0.1 & -34.218 & 0/07/2011 & -3.802 & -32.466 & $178 \mathrm{~d}$ \\
\hline AOCS4 & $197^{*}$ & $\mathrm{~F}$ & Atlantic & MiniPAT & $140 \mathrm{~d}$ & 06/12/2011 & -3.589 & -34.918 & $25 / 04 / 2012$ & -18.754 & -35.771 & $141 \mathrm{~d}$ \\
\hline AOCS5 & $180^{*}$ & $\mathrm{~F}$ & Atlantic & MiniPAT & $140 \mathrm{~d}$ & 01/03/2012 & -0.501 & -37.354 & $20 / 07 / 2012$ & 3.215 & -41.015 & $141 d^{* * * *}$ \\
\hline AOCS6 & 134 & $\mathrm{~F}$ & Atlantic & MiniPAT & $100 \mathrm{~d}$ & 02/03/2012 & -0.736 & -37.534 & $11 / 06 / 2012$ & -0.598 & -36.235 & $101 \mathrm{~d}$ \\
\hline AOCS7 & 161 & $\mathrm{~F}$ & Atlantic & MiniPAT & $100 \mathrm{~d}$ & 02/03/2012 & -0.435 & -37.629 & $14 / 06 / 2012$ & 1.306 & -35.345 & $104 \mathrm{~d}$ \\
\hline IOCS1 & $183^{*}$ & $\mathrm{~F}$ & Indian & MiniPAT & $100 \mathrm{~d}$ & $15 / 04 / 2011$ & -13.119 & 44.967 & $24 / 07 / 2011$ & -2.522 & 53.554 & $100 \mathrm{~d}$ \\
\hline
\end{tabular}

*Mature individuals (size at first maturity: $180 \mathrm{~cm} \mathrm{TL}$ ).

***ecovered tag.

***Tag stopped recording data after $104 \mathrm{~d}$ of deployment.

on the daily geolocation estimates from the tags and the NOAA daytime estimation algorithm (NOAA Solar Calculator, website). Day was defined as the period between sunrise and sunset, and night was defined as the period between astronomical dusk and astronomical dawn. Dusk was the hours between sunset and astronomical dusk, and dawn was the hours between astronomical dawn and sunrise. Because sharks made extensive horizontal movements during their monitoring periods, local sunrise and sunset times varied with time for all individuals. The variation, however, was not greater than $50 \mathrm{~min}$. To facilitate graphic representations of aggregated data, day and night and dawn and dusk were depicted by their respective minimum and maximum estimated times. Daytime and nighttime depths were compared with the nonparametric Wilcoxon test at a 95\% confidence level. For this analysis, depths corresponding to crepuscular hours (dawn and dusk) were excluded. Mean depths were grouped into 1-h intervals to test for uniformity over the 24-h cycle. The uniformity was tested by using circular statistics (Rao's spacing test), also at a 95\% confidence level.

A spectral analysis was carried out with the depth time-series data from the recovered tag of shark AOCS3. This analysis was not feasible for the other tags because of gaps caused by the data transmission. The aim was to identify a potential periodicity in the vertical behavior of this shark and infer possible temporal patterns. A fast Fourier transform algorithm was used in the stats package in $\mathrm{R}$, vers. 3.1.2 ( $\mathrm{R}$ Core Team, 2014). The function calculates a smoothed periodogram by using Daniell windows, which are modified moving-average filters. The raw periodogram is a widely fluctuating estimate of the spectrum with high variance, and this smoothing method provides a stable estimate (Bloomfield, 2004). The spectral analysis is particularly well suited for long-term and high-resolution time series, including those from archival tagging studies (Shepard et al., 2006).

The depth time-series data were also assessed visually to examine any possible vertical patterns that could have been masked when the data were grouped. This analysis was conducted with the help of a visualization tool, and the window of this software was adjusted on our computer screen to fit $2 \mathrm{~d}$ of data at a time. In this analysis, the times of sunrise and sunset did not need to be estimated. Instead, the readings of ambient light from the tags could be simultaneously displayed with the depth readings. The light data were transmitted in the form of 2 daily light curves, representing sunrise and sunset. For the recovered tag, the complete time series of light readings was available. The simultaneous visualization of light curves and the depth time series was created by using the graphing and analysis software program Igor Pro, vers. 6.22A (WaveMetrics Inc., Portland, OR). A suite of data analysis programs (WC-DAP, Wildlife Computers Inc.) was used to export a file formatted for use with Igor Pro, which facilitated the visual analysis. This pairing of light and depth data also increased the precision needed for discerning diel patterns.

Vertical movements and the environment To reconstruct the thermal signature of the water column occupied by the oceanic whitetip sharks during the periods in which they were monitored, the summary data for temperature at depth were used. This data product provides the minimum and maximum temperatures at selected 8-m depth intervals at a user-defined resolution (for this study, the resolution was every $24 \mathrm{~h}$ ). The average temperatures of depth intervals were interpolated linearly to produce continuous daily temperature 
profiles in a grid with a $0.5-\mathrm{m}$ resolution, according to the method described in Bauer et al. (2015). The interpolated temperature profiles were then plotted by using a heat-color scheme and examined in comparison with daily average depths and their standard deviations (SDs). This method was chosen because it has been shown to provide an accurate representation of the thermal signature and, therefore, to be a viable alternative in the absence of temperature time-series data (Bauer et al., 2015).

To identify potential environmental variables that could drive the vertical behavior of oceanic whitetip sharks, we applied generalized additive models (GAMs). This type of model has been used to model habitat preferences of a variety of oceanic species, including sharks (Zagaglia et al., 2004; Damalas and Megalofonou, 2010; Bustamante and Bennett, 2013; Lam et al., 2014). The daily SD of depth records was considered a proxy for the vertical variability (movement amplitude) of sharks and, therefore, was chosen as a response variable. The explanatory variables included environmental variables related to data derived from tag records: geolocation estimates (longitude and latitude), SST, mixedlayer depth (MLD), and shark size. These variables were introduced as smoothing terms (thin-plate regression splines). To assess temporal effects, "month" was included as a factorial variable. Because sharks were tagged in 2 ocean basins (Atlantic and Indian oceans), "ocean" was also included as a factorial variable. Modeling was conducted by using the gam function of the mgcv package, vers. 1.8-12, in $\mathrm{R}$ (Wood, 2006), with a Gaussian link function. All possible combinations between variables and factors were tested and yielded 63 models. Models also were run separately for each individual shark to investigate individual variability. In this case, "ocean" and "shark size" were not considered, resulting in 15 models. Model selection was based on the Akaike information criterion and further evaluated with residual analysis.

\section{Results}

\section{Vertical movement patterns}

Diel cycles Diel changes in vertical behavior were visible across the depth time series of all tagged individuals. However, different patterns also were observed within and between individuals. The strongest signal was observed during crepuscular hours, especially at dawn, when sharks swam at considerably shallower depths (Fig. 1). This pattern was consistent, and it frequently was observed in the time series of all individuals. Circular statistics, applied to the average depth per hour of each individual, revealed a lack of uniformity over a 24-h cycle for the oceanic whitetip sharks (Rao's spacing test: $P>0.001$ ). Test results highlight the consistency of this crepuscular pattern, which was present even when day and night differences were not observed.
Figure 1 also shows a general pattern of shallower average depths during the day than during night, when tagged sharks appear to move to deeper waters. This pattern was well marked for sharks AOCS4, AOCS5, AOCS7, and IOCS1, for which statistically significant differences were observed between occupied depths during light and dark hours (Suppl. Table 1). For sharks AOCS3 and AOCS6, a difference between day and night average depths was not evident or statistically significant. As opposed to the averages, SD values in depth records did not vary much across the 24-h cycle (Fig. 1). In contrast, for sharks IOCS1 and AOCS4, SD values were higher during the night than during the day. With SD considered a proxy of vertical amplitude, these sharks appear to explore the water column more extensively during nighttime.

The spectral analysis of high-resolution depth time series from the recovered tag of shark AOCS3 revealed 2 distinct frequency peaks, one at $12 \mathrm{~h}$ and another at $24 \mathrm{~h}$ (Fig. 2). The sharp 12-h peak might represent the crepuscular pattern described previously. The sharpness of this peak also indicates a high degree of consistency in this diel pattern, i.e., a shift in the vertical behavior frequently occurred around the same time of the day. The 24-h peak indicates that periodic behavioral shifts also occur with daytime and nighttime depths. The broad base of this peak, however, indicates that the shifts in vertical behavior at this scale are less consistent. This result is interesting in that it did not appear when the depth readings were aggregated by hour. In Figure 1 differences between daytime and nighttime average depths of this individual are not presented.

The visual assessment of each depth time series revealed the identification of 3 main types of day and night behavioral patterns. Type-I behavior was characterized by a preference for shallower waters and by some sporadic deep dives during the day and by a preference for deeper waters and regular up-and-down movements during the night. Type-II behavior featured an inverse pattern of that described as type I; sharks occupied deeper waters during the day, as opposed to night, and also made regular up-and-down movements. In contrast, type-III behavior did not show a clear difference between daytime and nighttime depth preferences. Examples of each behavior type can be seen in Figure 3. All individuals exhibited the 3 described behavioral patterns during their monitoring periods, but the frequency of each behavior type varied largely among sharks (Fig. 4). Type II was the least frequent behavior type observed in all time series and occurred most often for shark AOCS3, representing $23.7 \%$ of the time series of this individual. Type I dominated the time series of sharks AOCS4 (41.0\%) and IOCS1 $(61.2 \%)$, and type III dominated the time series of sharks AOCS5 (62.8\%) and AOCS6 (50.5\%). Note that because of gaps in the transmitted depth time-series data, not all 24 -h periods could be observed and hence classified.

The temporal distribution of behavior types did not 


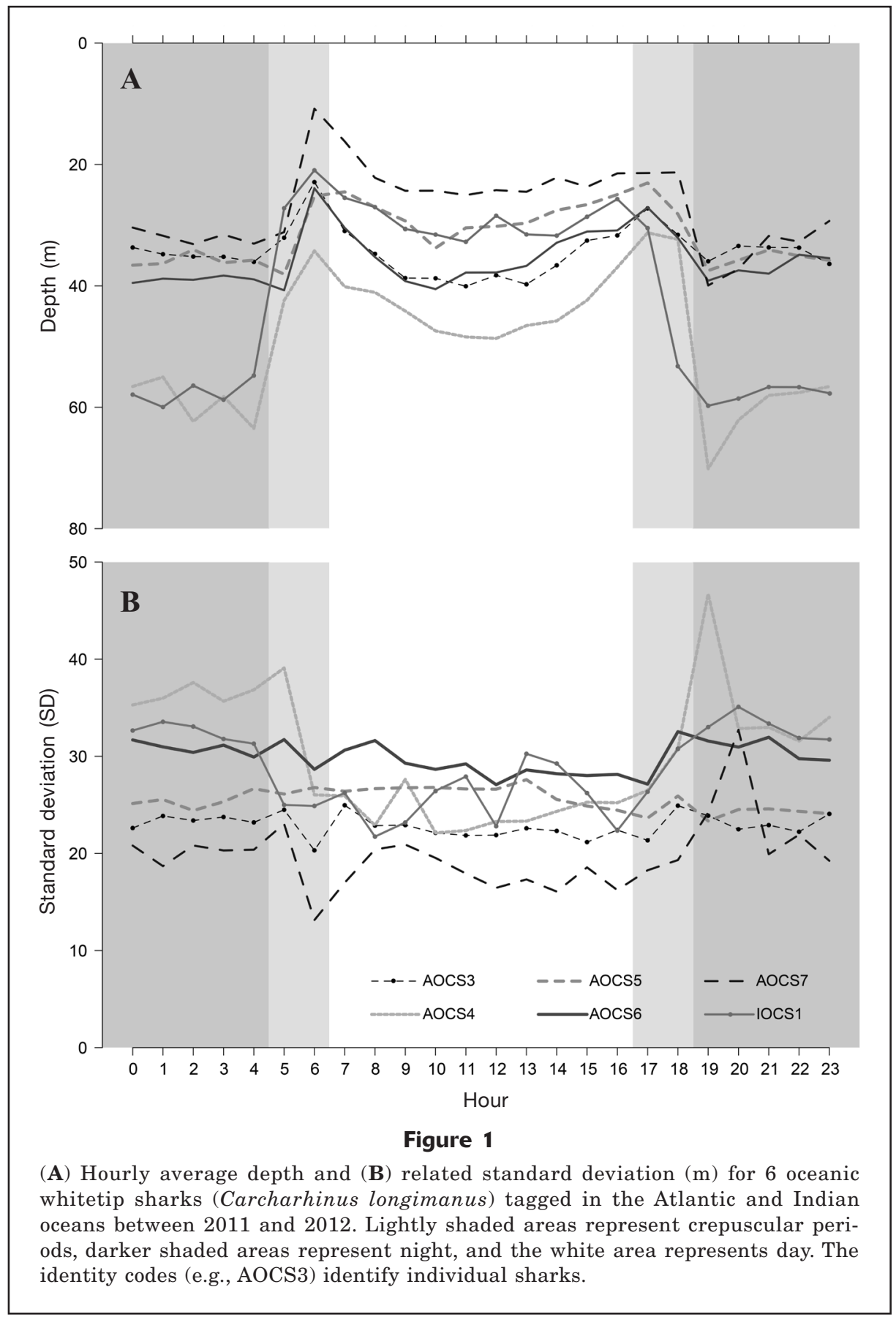

appear to be uniform, nor did they follow any particular pattern (Suppl. Fig. 2). Shark AOCS3, for instance, exhibited all 3 types of behavior almost in the same proportion (Fig. 4), and these behavior types alternated frequently throughout its time series. Long sequences of the same behavior type were rare for this individual, the maximum being 9 consecutive days for type I. In fact, long sequences of one behavior type were seen only when a particular type was also dominant for an individual, such as type I for shark IOCS1 and type III for shark AOCS5. For all sharks, one isolated day of any behavior type occurred more frequently than any sequence of one type of behavior. Only for one individual, shark AOCS4, was there a clear shift in behavior type with time observed. During its first 50 days of monitoring, this shark almost exclusively exhibited type-I behavior. After this period, shark AOCS4 started to alternate type I with the other behavior types. At the same time, the number of gaps present in the first 50 days of the time series for this shark weakened the veracity of this otherwise constant pattern.

Three sharks (AOCS5, AOCS6, and AOCS7) were 


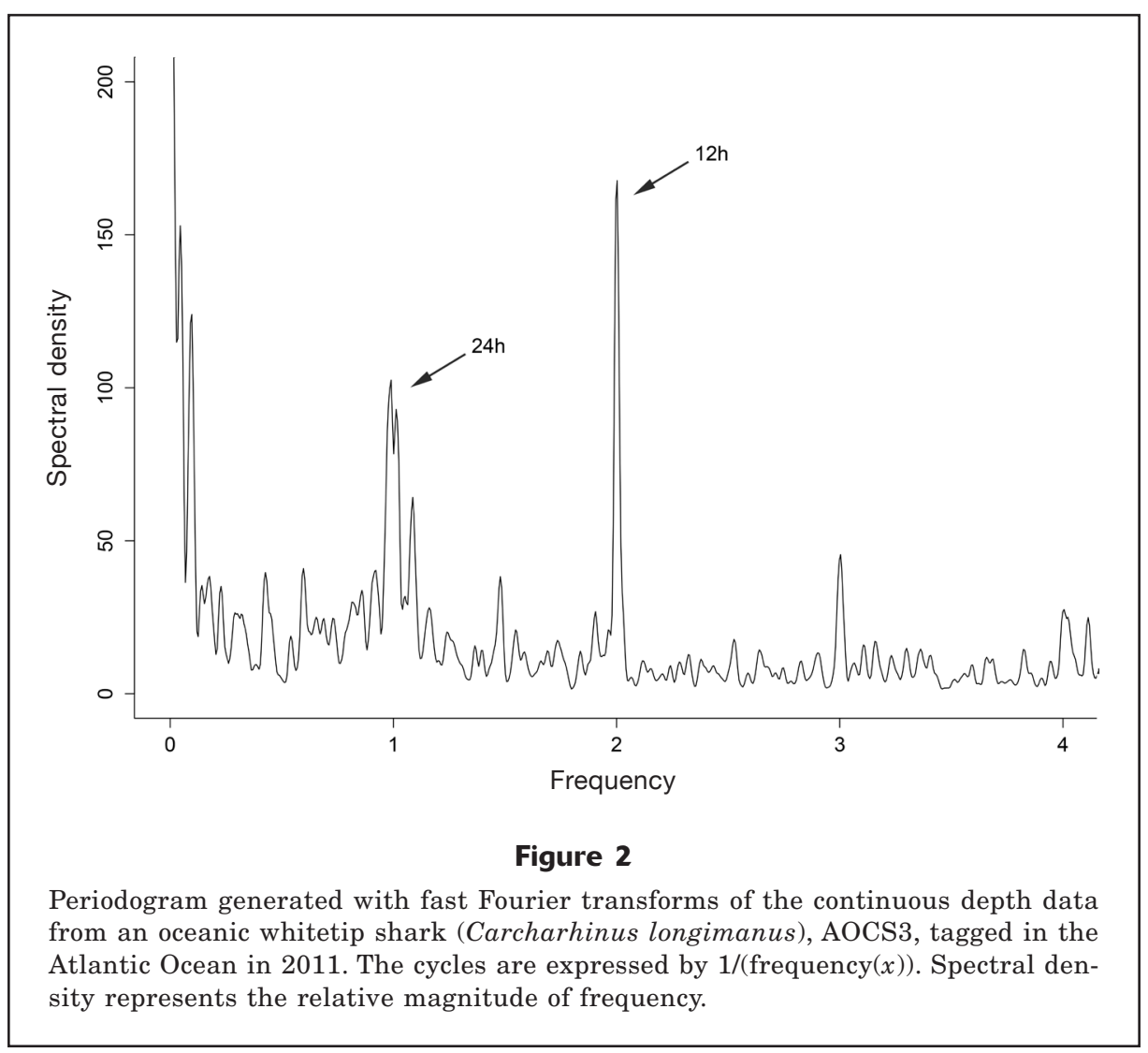

tagged on the same day at similar locations, and the duration of their monitoring period was the same. This unique situation facilitated the incorporation of a spatial aspect in the discussion concerning shifts between behavior types. The proportions of the 3 behavior types were linked across the tracks of these individuals (Fig. 5). Considering that individuals that are simultaneously at the same location typically also experience the same environment, this analysis revealed moments where environmental factors could have been the driver for the behavior of these sharks. At the beginning of May 2012, for example, sharks AOCS5 and AOCS7 were in the same square of latitude and longitude and had a similar behavioral pattern. Shark AOCS6, on the other hand, was in another location and had a different behavioral pattern. In fact, this shark remained in the same area for most of May, but its behavior pattern shifted completely between the first and second half of the month. Again, an environmental factor may have been the driver. However, during the second half of April, sharks AOCS5 and AOCS7 were at the same location exhibiting completely different behavioral patterns. This trend appeared again during the second half of May, indicating that the physical environment might not be the only driver of behavior types.

Spike dives While examining the time series, we noted that all individuals stayed primarily within the top 150 $\mathrm{m}$ of water but descended on rare occasions to depths below $150 \mathrm{~m}$. By looking closely at these rare deep diving events, which accounted for only $0.15 \%$ of the monitoring periods (Tolotti et al., 2015b), we identified common features. These features, referred to as spike dives, were characterized by rapid descents to depths greater than $150 \mathrm{~m}$, followed by considerably slower ascents. Two examples of spike dives can be seen in Supplementary Figure 3. All individuals performed spike dives during their monitoring period, and estimated descent rates varied from 0.14 to $1.05 \mathrm{~m} / \mathrm{s}$ and ascent rates varied from 0.08 to $0.26 \mathrm{~m} / \mathrm{s}$ (Table 2). Most of the spike dives lasted from 30 to $45 \mathrm{~min}$, but spike dives of more than $1 \mathrm{~h}$ also were noted. With the exception of movements of shark AOCS7, spike dives occurred primarily during the day (Suppl. Fig. 4). Besides performing the great majority of its spike dives during nighttime, shark AOCS7 also exhibited this behavior much more frequently than the other individuals.

\section{Vertical movements and the environment}

Daily average depths and SDs were plotted on top of temperature profiles to identify possible links between vertical movements and the thermal structure of the water column. Although some thermal changes were observed, the daily average depths were stable for all sharks (Fig. 6). The daily SD of depth records, on the other hand, indicated some variation. For sharks IOCS1 and AOCS6, for example, higher SD values were ob- 


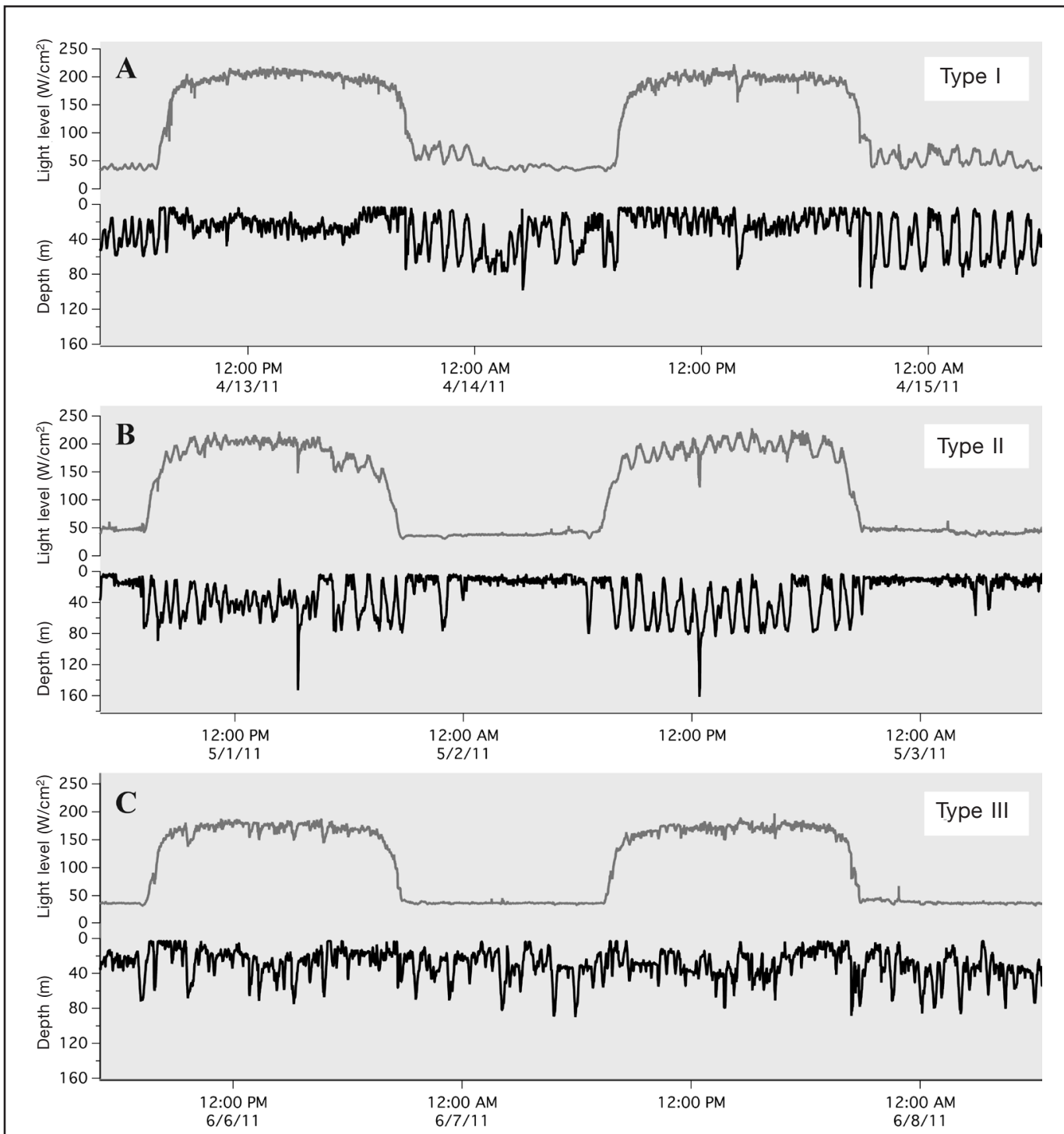

Figure 3

Examples of the 3 behavior types, or patterns of vertical movement, during day and night, of oceanic whitetip sharks (Carcharhinus longimanus) identified by visual assessments of depth data from sharks tagged in the Atlantic and Indian oceans between 2011 and 2012: (A) type-I, (B) type-II, and (C) type-III behavior.

served during June-July and early May, respectively, than during other periods. The observation of higher SD values coincided with a larger mixed layer, indicating that oceanic whitetip sharks have a greater depth range when their preferred environment is expanded. Sea-surface temperature also appears to influence vertical behavior. Careful inspection of Figure 6 for sharks AOCS3, AOCS6, and AOCS7 reveals that these individuals explored colder waters during periods of higher SST.

To better understand the influence of environmental conditions on the vertical behavior of the oceanic whitetip sharks in this study, several GAMs were applied. The results from these models were in accor- dance with the patterns in daily temperature-at-depth profiles estimated from tag data and depth SDs presented in Figure 6. The best models consistently indicated a significant influence of horizontal position (longitude and latitude), MLD, and SST on daily vertical activity (SD of daily depth records). Results from the model with combined data from all sharks indicate an additional effect of shark size and explain $50.1 \%$ of the deviance (coefficient of multiple determination $\left[R^{2}\right]=0.48, n=685$ ). Results from this model indicate an increase of vertical amplitude with the increase of the MLD and shark size. Sea-surface temperature follows the same trend, but it was the least significant factor 


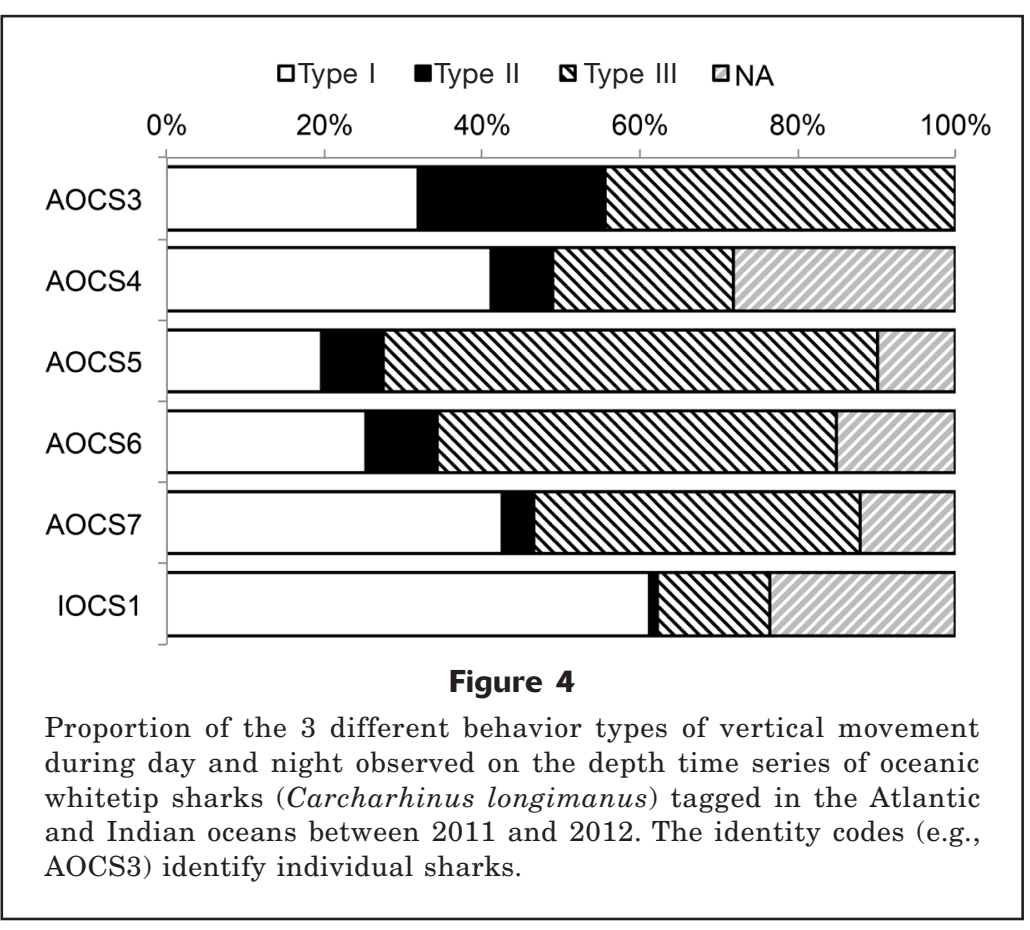

in the model with data from multiple sharks (Fig. 7). The set of explanatory variables in the best models for individual sharks varied slightly between sharks, and horizontal positions, unlike MLD and SST, were always significant (Fig. 7). Summary tables with model results are presented in Supplementary Table 2 and Supplementary Figure 5.

To assess in detail the effect of environmental factors on variations of vertical movement, the cumulative sums of MLD, SST, and depth SD were plotted for each individual. The cumulative sums were subtracted from the mean and rescaled to highlight periods when values were above or below the mean (Fig. 8). These plots reflect and facilitate understanding of the model results. The results for shark IOCS1 provide an example of the overall observed trend. For this individual, a perfectly aligned correlation between MLD and vertical activity was observed. When MLD was above average and, therefore, the species preferred environment was extended, the SD was also above average. The opposite trend was also true. It is not surprising that the MLD was a highly significant factor in the GAM for this individual; the GAM had a high degree of deviance explained (64.7\%). Another interesting case is shark AOCS3. In the beginning of the monitoring period for this shark, the same relationship with MLD and vertical activity (SD), as that found for IOCS1, was observed. Around May, however, a major shift occurred. Instead of decreasing with MLD, vertical activity of this shark started to increase regardless of the reduction of preferred environment. At this time, the SST started to exceed average values; hence, its addition as a significant factor in the model of AOSC3. This same trend was observed for shark AOCS5.

\section{Discussion}

Recent studies have shown that the oceanic whitetip shark is an epipelagic predator largely confined to the mixed layer (Musyl et al., 2011; Howey-Jordan et al., 2013; Tolotti et al., 2015b) - a finding that was also confirmed with this study. To date, however, detailed information on how this species occupies the epipelagic environment has been lacking. This study revealed that oceanic whitetip sharks had complex vertical movement patterns, pronounced diel changes and behavioral shifts, and that environmental factors influenced vertical activity. Several statistical approaches were combined to identify these vertical movement patterns. This research represents the first description of satellite archival data from a tag deployed on an oceanic whitetip shark in the Indian Ocean.

\section{Diel patterns}

The occurrence of diel behavior has not been reported from previous research on vertical movements of oceanic whitetip sharks (Howey-Jordan et al., 2013). Conversely, diel patterns were observed for all 6 individuals analyzed in our study. Despite some variability, diel patterns occurred at least once during the monitoring period of each tagged shark. Diel vertical movements are very common for fish species with vertical ranges that exceed that of oceanic whitetip sharks, such as the blue shark (Prionace glauca), bigeye thresher (Alopias superciliosus), swordfish, and bigeye tuna (Thunnus obesus) (Musyl et al., 2003, 2011; Abecassis et al., 2012; Lam et al., 2014; Coelho et al., 2015). These species usually occupy deep waters during the day and remain in the mixed layer during the night. They are believed to follow the vertical migration of mesopelagic prey species within the deep scattering layer (Dagorn et al., 2000; Bernal et al., 2009).

Several epipelagic predators have also been reported to display diel patterns in their vertical behavior. For the silky shark (C. falciformis) and dolphinfish (Coryphaena hippurus) (Merten and Appeldoorn, 2014; Filmalter et al., 2015), for example, vertical movements similar to the type-I behavior described previously for the oceanic whitetip shark have been observed. Although opposite to the general diel migration pattern described for pelagic species with wide vertical ranges, type-I behavior could also be linked to feeding on mesopelagic prey from the deep scattering layer. Filmalter et al. (2015) reported that silky sharks during the night were more vertically active and were observed at depths similar to the nocturnal depth range of pelagic species known to follow the migration of the deep scattering layer. The authors hypothesized that these increased vertical oscillations were associated with feeding activity. 


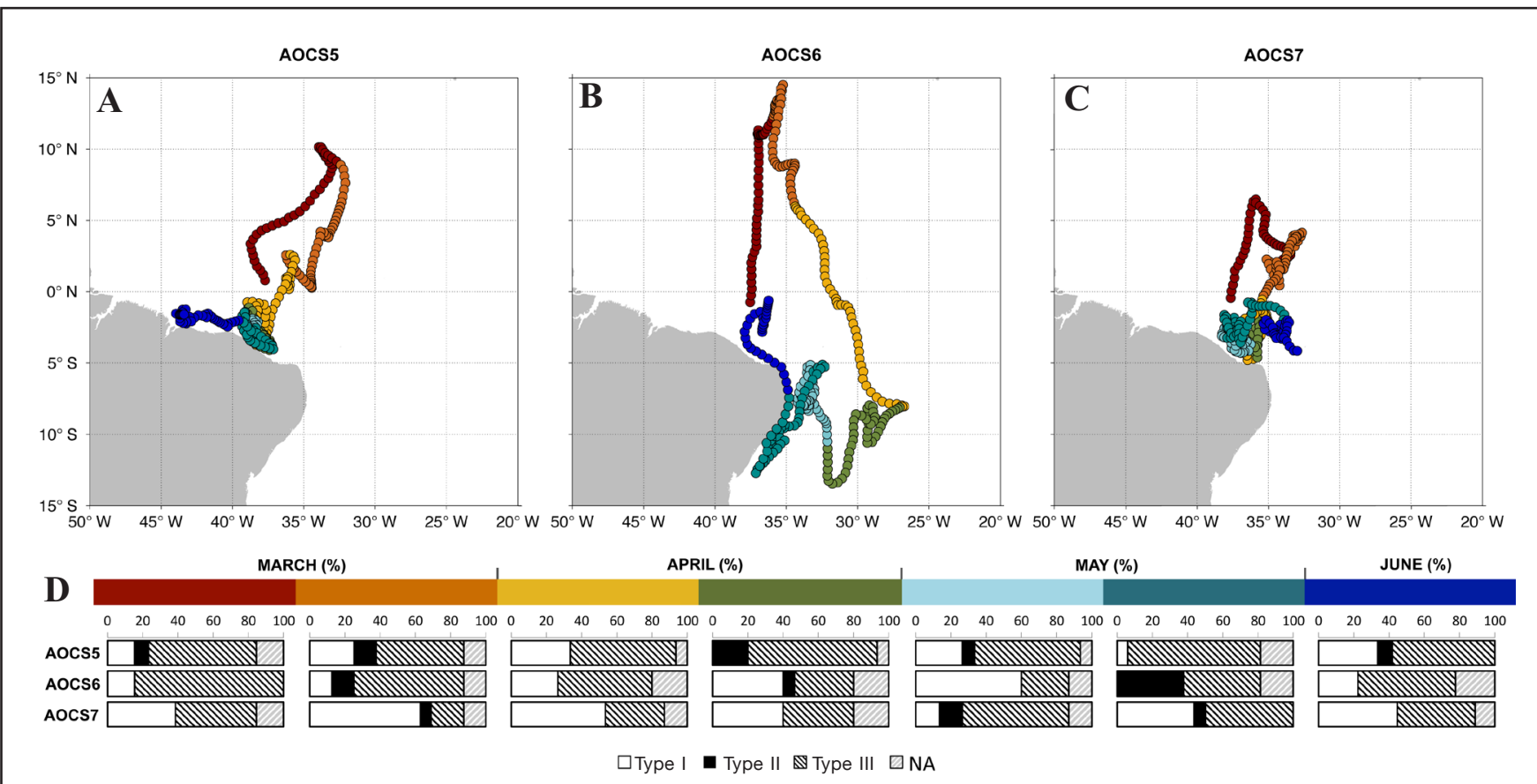

Figure 5

Tracks of 3 oceanic whitetip sharks (Carcharhinus longimanus) tagged off northeast Brazil in the Atlantic Ocean at a 24-h interval in March 2012, (A) AOCS5, (B) AOCS6, and (C) AOCS7, and (D) the proportion of the 3 behavior types of vertical movement across those tracks. The 2 colors for each month indicate the first and second halves of the month.

\begin{tabular}{|c|c|c|c|c|c|}
\hline \multicolumn{6}{|c|}{ Table 2} \\
\hline \multicolumn{6}{|c|}{$\begin{array}{l}\text { Summary of data on the spike dives performed by oceanic whitetip sharks (Car- } \\
\text { charhinus longimanus) during monitoring with pop-up satellite archival tags in } \\
\text { the Atlantic and Indian oceans in } 2011 \text { and } 2012 \text {. }\end{array}$} \\
\hline ID & $\begin{array}{l}\text { Number of deep } \\
\text { spike dives }\end{array}$ & $\begin{array}{c}\text { Max depth } \\
\text { range }(\mathrm{m})\end{array}$ & $\begin{array}{l}\text { Duration } \\
\quad(\min )\end{array}$ & $\begin{array}{c}\text { Descent rate } \\
\text { range }(\mathrm{m} / \mathrm{s})\end{array}$ & $\begin{array}{l}\text { Ascent rate } \\
\text { range }(\mathrm{m} / \mathrm{s})\end{array}$ \\
\hline AOCS3 & 4 & $237-365$ & $21-45$ & $0.55-1.00$ & $0.10-0.24$ \\
\hline AOCS4 & 4 & $232-340$ & $35-75$ & $0.14-0.49$ & $0.12-0.22$ \\
\hline AOCS5 & 3 & $154-193$ & $40-55$ & $0.19-0.23$ & $0.08-0.12$ \\
\hline AOCS6 & 2 & $181-277$ & 45 & $0.17-0.40$ & $0.09-0.12$ \\
\hline AOCS7 & 18 & $153-405$ & $30-65$ & $0.44-1.05$ & $0.15-0.26$ \\
\hline IOCS1 & 6 & $257-317$ & $35-50$ & $0.22-0.89$ & $0.14-0.17$ \\
\hline
\end{tabular}

In our study, indication of an increased vertical activity during the night also was found (see Fig. 1). Moreover, oceanic whitetip sharks are known to feed on mesopelagic squids (Backus et al., 1956), and stable isotopes in a recent study have indicated that there is an almost equal importance of squids (44\%) and larger pelagic teleosts (47\%) in their diet (Madigan et al., 2015). Deep excursions of oceanic whitetip sharks are rare and are, therefore, unlikely to account for such a significant portion of a mesopelagic species in the diet of this shark. This fact indicates that type-I behavior indeed can be linked to feeding on prey from the deep scattering layer during the night.

Variability in vertical movement patterns has also been reported for several pelagic fish species. Blue sharks are known for their marked diel migration to shallower waters during the night, but 5 distinct vertical behavior types have been described recently for that species (Queiroz et al., 2012). These behavior types ranged from the general, known diel pattern to their inverse and included patterns for which no diel differences were apparent, as we have described for 


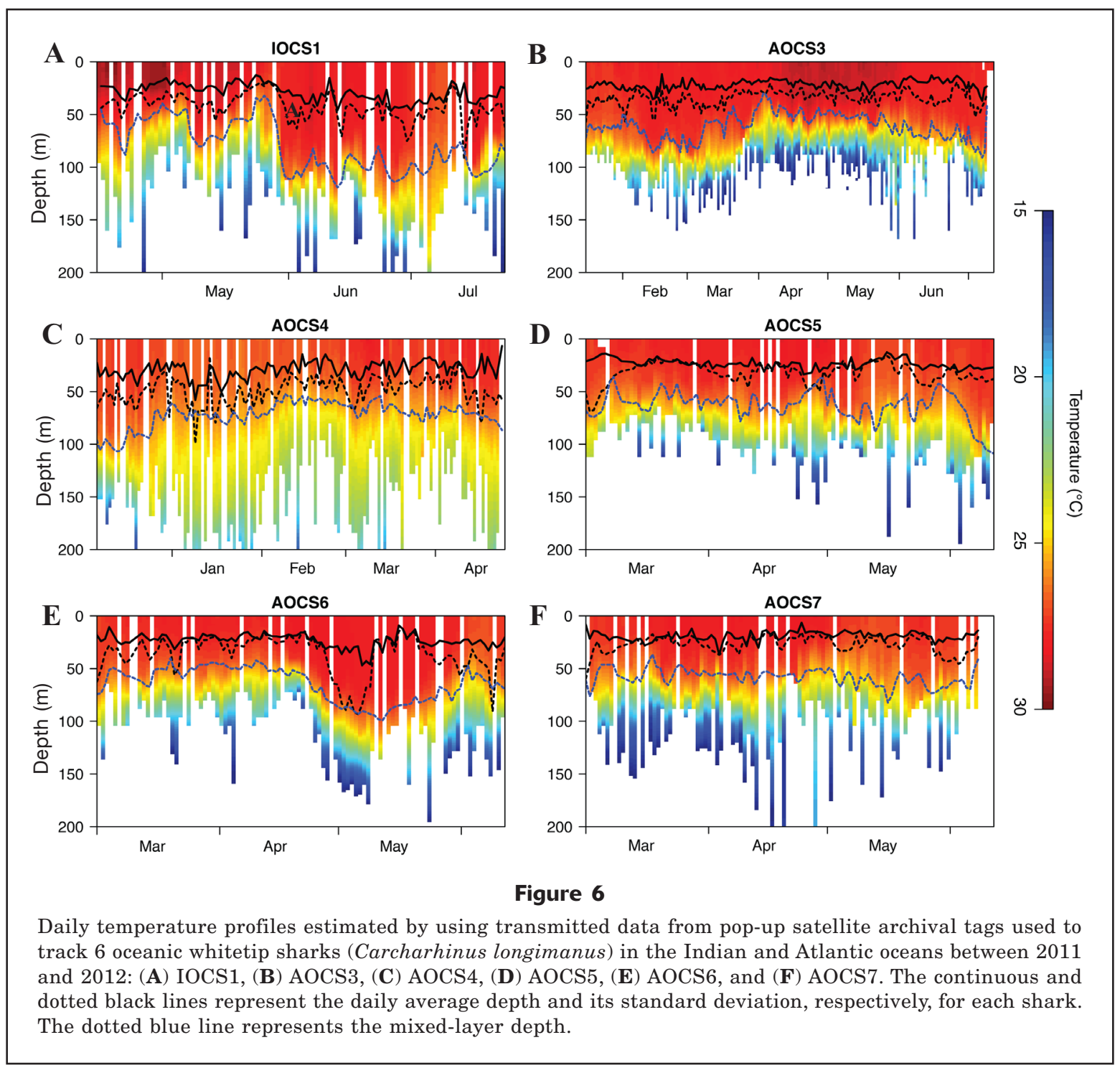

oceanic whitetip sharks in this study (type-III behavior). Contrasting diel vertical behavior types have also been reported for the porbeagle (Lamna nasus) and plankton-feeding basking shark (Cetorhinus maximus) (Sims et al., 2005; Pade et al., 2009). These behaviors are believed to be linked to prey availability. The studies cited above show that shifts in diel vertical behavior occur when the sharks change their environment, for example, when they move from mixed coastal waters to well-stratified offshore waters (Pade et al., 2009; Queiroz et al., 2012), or when they mirror prey behavior (Sims et al., 2005).

For the oceanic whitetip sharks tagged in our work, it was not possible to identify clear temporal or spatial patterns in the occurrence of the different behaviors. The types of behavior alternated frequently and no pattern was observed across the time series (Fig. 5, Suppl. Fig. 2). Oceanic whitetip sharks are opportunistic predators (Backus et al., 1956; Compagno, 1984), and the variability observed in the vertical movement patterns of the sharks in our study could very well be linked to prey distribution, as has been suggested for other pelagic sharks. Additional research using simultaneous data collection on prey distribution and tagging experiments would be required to verify this hypothesis. A comparison of the vertical behavior of other pelagic sharks tagged in the same areas could also provide useful information.

The fast Fourier transform analysis of depth data from the recovered tag (shark AOCS3) revealed 2 distinct frequency peaks, at 12 and $24 \mathrm{~h}$, indicating a pronounced periodicity in the vertical movements of this shark (Fig. 2). The peak at $24 \mathrm{~h}$ confirms the diel behavior, and its broad base indicates a certain degree of variability. Peaks corresponding to a 24 -h cycle have been observed for other pelagic shark species, and such peaks are typically interpreted as evidence of diel behavior (Brunnschweiler and Sims, 2012; Filmalter et 


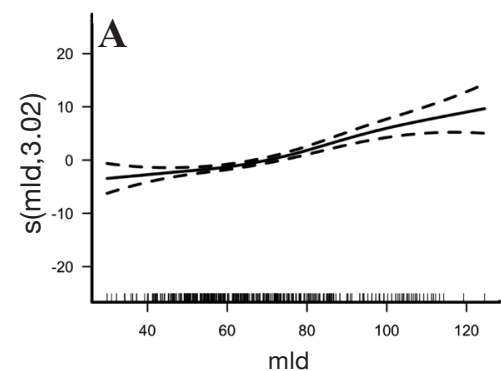

IOCS1: depth SD s(long, lat $)+s(m l d)$

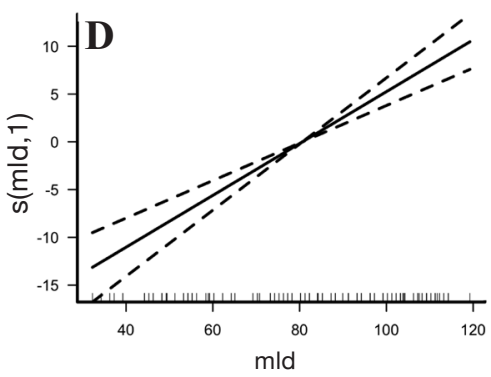

AOCS5: depth SD $\sim \mathrm{s}$ (long, lat $)+\mathrm{s}(\mathrm{mld})+\mathrm{s}(\mathrm{SST})$
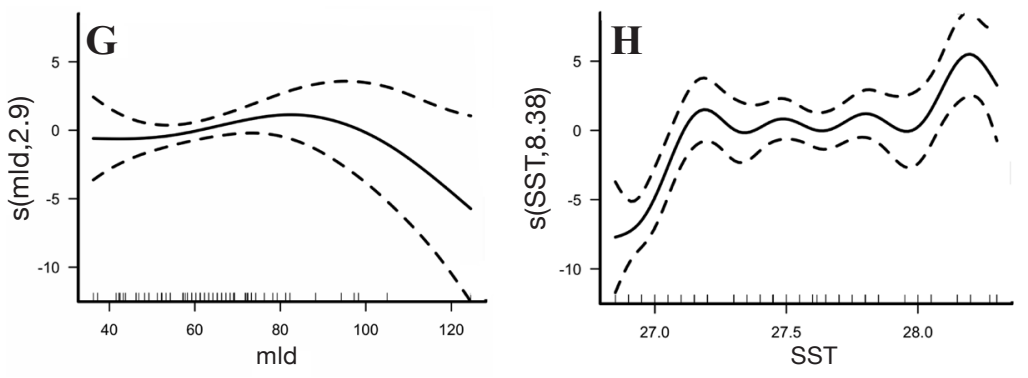

AOCS6: depth SD $\sim \mathrm{s}($ long, lat $)+\mathrm{s}(\mathrm{mld})+\mathrm{s}(\mathrm{SST})$
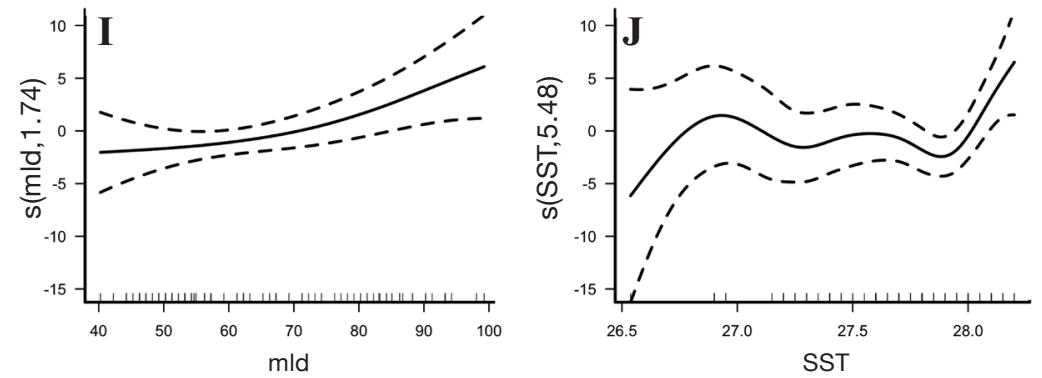

Figure 7
ALL: depth $S D \sim s($ long, lat $)+s($ mld $)+s(S S T)+s($ size,$k=6)$
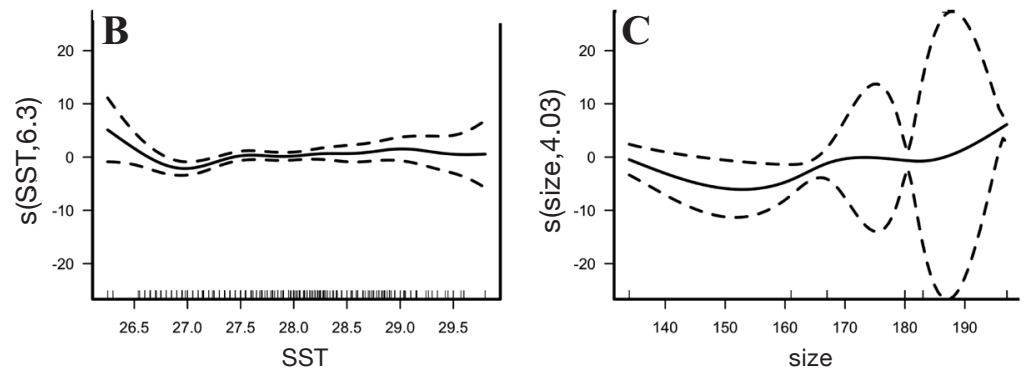

AOCS3: depth SD s(long, lat $)+s(m l d)+s(S S T)$
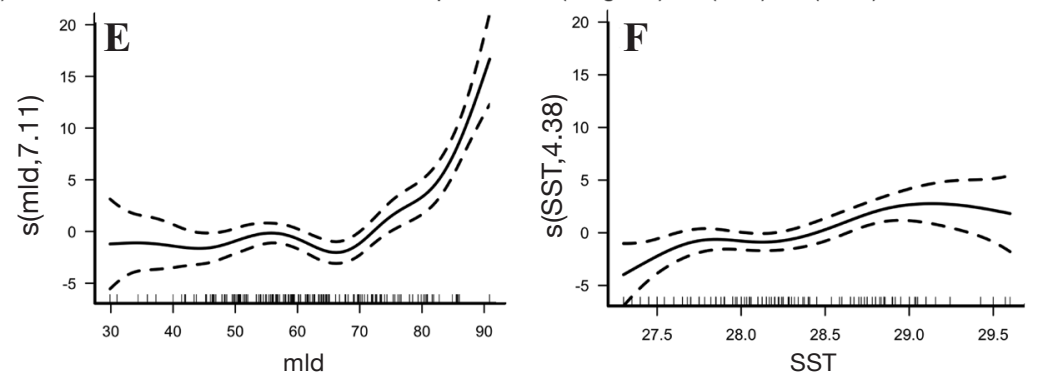

AOCS7: depth SD s(long, lat $)+\mathrm{s}(\mathrm{SST})$

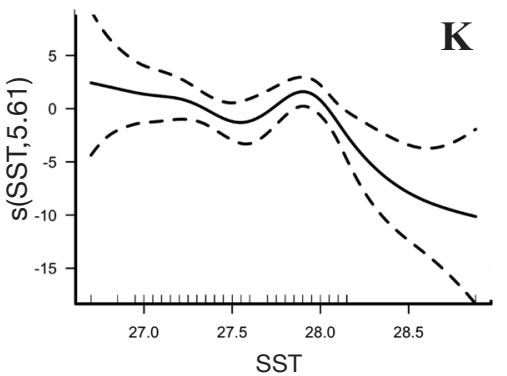

Formulas and corresponding smoothing terms (thin-line regression splines, black lines) with 95\% confidence intervals (dotted lines) for the best-fitted generalized additive models used in this study of vertical movements of oceanic whitetip sharks (Carcharhinus longimanus). The models were based on data from 6 tagged oceanic whitetip sharks in the Atlantic and Indian oceans between 2011 and 2012, with the daily depth standard deviation (SD) as the response variable. Shown are the splines for (A) mixed-layer depth (MLD), (B) sea-surface temperature (SST), and (C) size for the model that used all 6 sharks, MLD for the model that used the shark tagged in the Indian Ocean (IOCS1) (D), MLD and SST for the models that used an individual shark tagged in the Atlantic Ocean-(E-F) AOCS3, (G-H) AOCS5, (I-J) AOCS6-and (K) SST for the model that used a shark tagged in the Atlantic Ocean (AOCS7). Splines (s) are not shown for a fourth smoothing term, longitude (long.) and latitude (lat). $\mathrm{K}=$ number of individuals. 


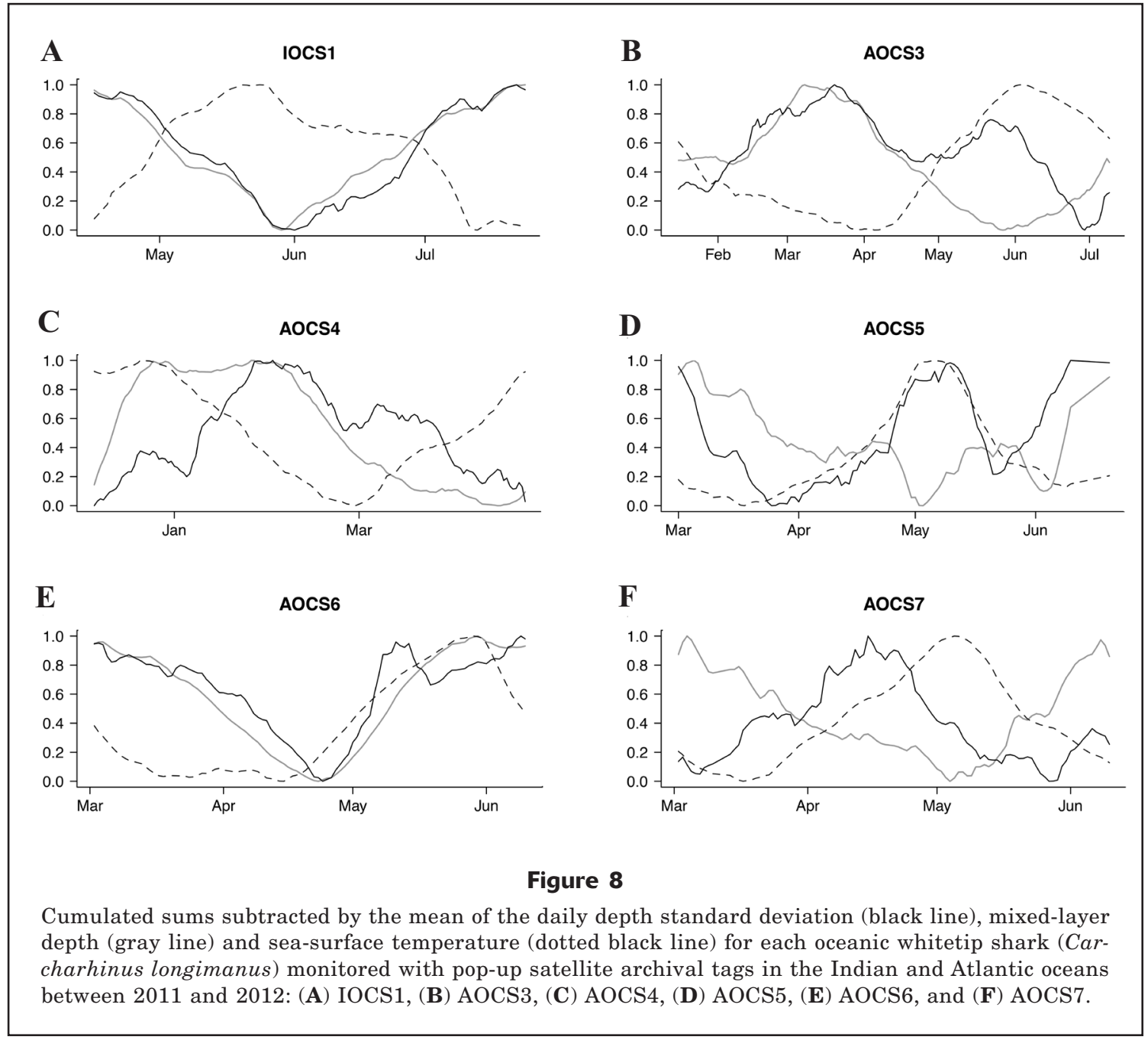

al., 2015; Tyminski et al., 2015). A 12-h periodicity in vertical behavior, however, has not been reported as often for pelagic species. Typically, a spectral peak at $12 \mathrm{~h}$ is observed for coastal species, and such peaks are strongly linked to tidal cycles (Urmy et al., 2012). Similar to the peak observed for shark AOCS3, the strongest spectral peak in the periodogram of a basking shark in another study had a period of $12.35 \mathrm{~h}$ (Shepard et al., 2006). The authors associated this peak with the tidal cycle because the shark remained on the continental shelf where there is clearly a tidal influence. In contrast, shark AOCS3 remained in oceanic waters (Suppl. Fig. 1) with a potentially weaker tidal signal. Therefore, it appears unlikely that the 12-h spectral peak observed for this oceanic whitetip shark was linked to any tidal cycle.

Instead, the $12-\mathrm{h}$ peak appears to be related to vertical crepuscular movements. The oceanic whitetip sharks analyzed in this study occupied considerably shallower depths during the hours of dawn and dusk than during other periods of the day (Fig. 1). Coinci- dentally, at equatorial latitudes, day and night have similar lengths, resulting in a crepuscular event every 12 h (World of Earth Science, 2003). Shark AOCS3 stayed at equatorial latitudes during its entire tracking period, indicating that the 12 -h spectral peak of vertical movement matches the crepuscular cycle. This dawn and dusk pattern of vertical movement was consistent throughout the time series of all 6 individuals, and it has been identified also in the behavior of oceanic whitetip sharks tagged in the Pacific Ocean (Musyl et al., 2011). The sharpness of the 12-h peak indicates that this crepuscular pattern represents a frequent and pronounced feature in the oceanic whitetip shark behavioral repertoire. Similar patterns have been reported for other shark species and have been associated with foraging behavior and maintaining a preferred isolume (Nelson et al., 1997; Vianna et al., 2013). In short, the variations in luminosity, characteristic of twilight hours, may represent the cues that regulate the behavioral shifts and feeding activity of this species. 


\section{Spike dives}

Oceanic whitetip sharks tagged in the North Atlantic Ocean (Bahamas) have been reported to make sporadic deep dives to the mesopelagic zone, down to a depth of $1190 \mathrm{~m}$ (Howey-Jordan et al., 2013; Howey et al., 2016). Similar to the deep dives observed in our work, descent rates of dives of oceanic whitetip sharks in the study off the Bahamas were significantly faster than ascent rates. However, unlike most sharks in our study, the sharks in the Bahamas performed deep dives primarily at night and dusk. The difference between the 2 studies in the period during which oceanic whitetip sharks made deep dives could be related to local environmental conditions; however, 1 shark (shark AOCS7) in our study also made spike dives primarily during the night. These contrasting periods and the rarity of these deep dives make it difficult to identify their driving forces. In any case, similarly shaped deep dives are relatively common among pelagic sharks and often are believed to be associated with prey searching (Sepulveda et al., 2004; Hoffmayer et al., 2013; Howey-Jordan et al., 2013; Tyminski et al., 2015). Gleiss et al. (2011) suggested that $\mathrm{v}$-shaped dives might help sharks to efficiently scan the water column for patches of food while expending minimal energy. They also suggested that slower ascent rates might improve the chances of pelagic predators detecting prey because backlighting is improved during ascents.

If searching for prey is the driver behind the occasional spike dives observed for oceanic whitetip sharks in our study, they could have been triggered after sharks remained in less productive surface waters for prolonged periods. It has been hypothesized that deep dives by whale sharks (Rhincodon typus) in the Indian Ocean were triggered when individuals were crossing less productive areas (Brunnschweiler and Sims, 2012). Another hypothesis for the occurrence of spike dives is that sharks make these deep dives to search for navigational cues through magnetic gradients (Willis et al., 2009). Seafloor magnetic anomalies associated with bathymetric features form a predictable gridded pattern that is believed to aid navigation (Walker et al., 2002). Sharks can detect magnetic fields (Kalmijn, 1982), and deep dives could represent a mechanism to acquire these magnetic cues (Gleiss et al., 2011; Tyminski et al., 2015). Howey et al. (2016) concluded that foraging or navigation are the only viable hypotheses to explain the reasons for the mesopelagic excursions of oceanic whitetip sharks, but they suggested that foraging is the most likely hypothesis. Nevertheless, the 2 proposed hypotheses are plausible and not mutually exclusive. It is, therefore, possible that isolated spike dives taken by oceanic whitetip sharks can be triggered by both foraging and navigational needs, depending on the circumstances.

\section{Vertical movements and the environment}

Water temperature is a limiting factor for ectothermic species whose body temperature is dependent on the external environment, because body temperature is a central factor in the control of their physiological processes (Sims, 2003). For such species, like the oceanic whitetip shark, which occupies the tropical epipelagic niche (Musyl et al., 2011; Howey-Jordan et al., 2013; Tolotti et al., 2015b), variations in the extent and heat content of the warmer mixed layer are expected to play a major role in their vertical movements. Our study confirmed this strong relationship by modeling the SD of daily depth records as a proxy for the amplitude of vertical movements. The GAM results indicate that tagged oceanic whitetip sharks tended to increase their vertical range in the water column as the depth of the mixed layer increased and, consequently, their optimal habitat expanded. A similar relationship was recently observed for another tropical epipelagic species; dolphinfish tagged in the Pacific Ocean extended their vertical depth ranges as the depth of the thermocline increased (Furukawa et al., 2014).

Besides the MLD, other factors were found to influence the vertical movements of tagged oceanic whitetip sharks in our study. Results from the GAM that used data for multiple sharks indicate an effect of shark size, in which larger individuals tended to have wider use of the water column. Values of average depth per hour, displayed in Figure 1, also indicate that vertical behavior might vary with shark size. Such an effect might be linked to the increased thermal inertia that results from a larger body mass, enabling larger individuals to extend their thermal habitat (Neill et al., 1974, 1976; Wilson et al., 2006). A possible effect of size on the vertical movements of oceanic whitetip sharks and silky sharks also has been reported from a tagging study conducted off Hawaii (Musyl et al., 2011). The results of a cluster analysis by Musyl et al. (2011) revealed that the vertical behavior of large individuals (>200 cm in total length) of these 2 closely related species appear to be well separated from that of juveniles.

For oceanic whitetip sharks tagged in the Bahamas, a correlation between average daily depth and SST was observed (Howey-Jordan et al., 2013). The authors reported that the average daily depth increased when individuals experienced warmer SSTs. For the oceanic whitetip sharks that we studied, the results from most GAMs also indicate a positive relationship between vertical movement and SST. Interestingly, for 2 individuals (AOCS3 and AOCS5), this relationship occurred simultaneously with an inverse relationship between MLD and the vertical activity of the sharks. In short, when SST was above average, these 2 sharks increased the amplitude of their vertical movement despite the reduced depth of the mixed layer. This pattern may indicate behavioral thermoregulation. Accordingly, oceanic whitetip sharks could be using the warmer SST to accumulate heat and subsequently explore cooler deep waters or they could be diving below the thermocline to cool down.

Howey-Jordan et al. (2013) also suggested that the correlation between SST and average depth observed for the oceanic whitetips sharks in the Bahamas could 
indicate a behavioral thermoregulation mechanism. In fact, the use or active avoidance of heat sources to regulate body temperature has been reported for other shark species (Campana et al., 2011; Speed et al., 2012; Vianna et al., 2013). There is evidence supporting the idea that behaviorally induced thermoregulation optimizes physiological and metabolic processes, reducing metabolic losses and increasing foraging efficiency (Sims, 2003; Campana et al., 2011). Unfortunately, the relatively small sample size of our study hampers a more detailed analysis and discussion concerning behaviorally induced thermoregulation on oceanic whitetip sharks. Although additional data are still required, the results presented here indicate that the accumulation of heat could play an important role in triggering vertical movements. It seems that warmer SST allows oceanic whitetip sharks to tolerate a greater temperature range and, therefore, to temporarily expand their vertical niche.

Longlining is the main gear responsible for the demise of populations of oceanic whitetip shark (Rice and Harley ${ }^{1}$. Given that the depth stratum of this fishing gear considerably overlaps with the vertical distribution of this species (Tolotti et al., 2015b), it is important to continue our efforts to understand the behavioral patterns of sharks and the drivers behind these patterns. It must be noted that when dealing with rare, threatened animals, such as the oceanic whitetip shark, sample size is constrained largely by opportunity. This study was based on only 6 individuals, but the observations over $538 \mathrm{~d}$ in the Atlantic Ocean and 100 $d$ in the Indian Ocean provide new information on the behavior of this shark. Nevertheless, the scientific community should direct its efforts to increase the number of tagged individuals, including tagging across a broader geographic region. Electronic tags are resourceful, nonlethal instruments that can significantly improve our knowledge of the ecology of this threatened species and, consequently, can aid its conservation.

\section{Acknowledgments}

We thank the crews, observers, and scientists involved in the tagging of oceanic whitetip sharks. We also thank A. Villareal and C. Taylor for returning the tag that was found stranded at a beach in Texas. This study was financed by the Commission of the European Communities Framework Program 7, Theme 2, through the research project "Mitigating adverse ecological impacts of open ocean fisheries." M. Tolotti received doctoral grants from the Coordenação de Aperfeiçoamento de Pessoal de Nível Superior and France Filière Pêche.

\section{Literature cited}

Abecassis, M., H. Dewar, D. Hawn, and J. Polovina.

2012. Modeling swordfish daytime vertical habitat in the North Pacific Ocean from pop-up archival tags. Mar. Ecol. Prog. Ser. 452:219-236. Article
Backus, R. H., S. Springer, and E. L. Arnold Jr.

1956. A contribution to the natural history of the whitetip shark, Pterolamiops longimanus (Poey). Deep Sea Res. 3:178-188. Article

Barker, M. J., and V. Schluessel.

2005. Managing global shark fisheries: suggestions for prioritizing management strategies. Aquat. Conserv. 15:325-347. Article

Bauer, R. K., F. Forget, and J.-M. Fromentin.

2015. Optimizing PAT data transmission: assessing the accuracy of temperature summary data to estimate environmental conditions. Fish. Oceanogr. 24:533-539. Article

Baum, J., E. Medina, J. A. Musick, and M. Smale.

2015. Carcharhinus longimanus. The IUCN Red List Threatened Species 2015: e.T39374A85699641. Article

Beerkircher, L. R., E. Cortés, and M. Shivji.

2002. Characteristics of shark bycatch observed on pelagic longlines off the southeastern United States, 19922000. Mar. Fish. Rev. 64(4):40-49.

Bernal, D., C. Sepulveda, M. Musyl, and R. Brill.

2009. The eco-physiology of swimming and movement patterns of tunas, billfishes, and large pelagic sharks. In Fish locomotion: an etho-ecological perspective (P. Domenici and D. Kapoor, eds.), p. 436-483. Science Publishers, Enfield, New Hampshire.

Bloomfield, P.

2004. Fourier analysis of time series: an introduction, 288 p. John Wiley \& Sons Inc., New York.

Bonfil, R., S. Clarke, and H. Nakano.

2008. The biology and ecology of the oceanic whitetip shark, Carcharhinus longimanus. In Sharks of the open ocean: biology, fisheries and conservation (M. D. Camhi, E. K. Pikitch, E. A. Babcock, eds.), p. 128-139. Blackwell Publishing Ltd., Oxford.

Brunnschweiler, J. M., and D. W. Sims.

2012. Diel oscillations in whale shark vertical movements associated with meso-and bathypelagic diving. Am. Fish. Soc. Symp. 76:457-469.

Bustamante, C., and M. B. Bennett.

2013. Insights into the reproductive biology and fisheries of two commercially exploited species, shortfin mako (Isurus oxyrinchus) and blue shark (Prionace glauca), in the south-east Pacific Ocean. Fish. Res. 143:174-183. Article

Camargo, S. M., R. Coelho, D. Chapman, L. Howey-Jordan, E. J. Brooks, D. Fernando, N. J. Mendes, F. H. V. Hazin, C. Oliveira, M. N. Santos, et al.

2016. Structure and genetic variability of the oceanic whitetip shark, Carcharhinus longimanus, determined using mitochondrial DNA. PLoS ONE 11(5):e0155623. Article

Campana, S. E., A. Dorey, M. Fowler, W. Joyce, Z. Wang, D. Wright, and I. Yashayaev.

2011. Migration pathways, behavioural thermoregulation and overwintering grounds of blue sharks in the northwest Atlantic. PLoS ONE 6(2):e16854. Article

Coelho, R., J. Fernandez-Carvalho, and M. N. Santos.

2015. Habitat use and diel vertical migration of bigeye thresher shark: overlap with pelagic longline fishing gear. Mar. Environ. Res. 112:91-99. Article

Compagno, L. J. V.

1984. FAO species catalogue, vol . 4. Sharks of the world: an annotated and illustrated catalogue of shark spe- 
cies known to date. Part 1-Hexanchiformes to Lamniformes. FAO Fish. Synop. 125, 249 p. FAO, Rome.

Dagorn, L., P. Bach, and E. Josse.

2000. Movement patterns of large bigeye tuna (Thunnus obesus) in the open ocean, determined using ultrasonic telemetry. Mar. Biol. 136:361-371. Article

Damalas, D., and P. Megalofonou.

2010. Environmental effects on blue shark (Prionace glau$c a$ ) and oilfish (Ruvettus pretiosus) distribution based on fishery-dependent data from the eastern Mediterranean Sea. J. Mar. Biol. Assoc. U.K. 90:467-480. Article

Filmalter, J., P. Cowley, F. Forget, and L. Dagorn.

2015. Fine-scale 3-dimensional movement behaviour of silky sharks Carcharhinus falciformis associated with fish aggregating devices (FADs). Mar. Ecol. Prog. Ser. 539:207-223. Article

Frédou, F. L., M. T. Tolotti, T. Frédou, F. Carvalho, H. Hazin, G. Burgess, R. Coelho, J. D. Waters, P. Travassos, and F. H. V. Hazin.

2015. Sharks caught by the Brazilian tuna longline fleet: an overview. Rev. Fish Biol. Fish. 25:365-377. Article

Furukawa, S., Y. Tsuda, G. N. Nishihara, K. Fujioka, S. Ohshimo, S. Tomoe, N. Nakatsuka, H. Kimura, T. Aoshima, H. Kanehara, et al.

2014. Vertical movements of Pacific bluefin tuna (Thunnus orientalis) and dolphinfish (Coryphaena hippurus) relative to the thermocline in the northern East China Sea. Fish. Res. 149:86-91. Article

Gallagher, A. J., E. S. Orbesen, N. Hammerschlag, and J. E. Serafy.

2014. Vulnerability of oceanic sharks as pelagic longline bycatch. Global Ecol. Conserv. 1:50-59. Article

Garcia, S. M., and K. L. Cochrane.

2005. Ecosystem approach to fisheries: a review of implementation guidelines. ICES J. Mar. Sci. 62:311-318. Article

Gleiss, A. C., B. Norman, and R. P. Wilson.

2011. Moved by that sinking feeling: variable diving geometry underlies movement strategies in whale sharks. Funct. Ecol. 25:595-607. Article

Hall, M., and M. Roman.

2013. Bycatch and non-tuna catch in the tropical tuna purse seine fisheries of the world. FAO Fish. Aquac. Tech. Pap. 568, 249 p. FAO, Rome.

Hoffmayer, E. R., J. S. Franks, W. B. Driggers, and P. W. Howey.

2013. Diel Vertical movements of a scalloped hammerhead, Sphyrna lewini, in the northern Gulf of Mexico. Bull. Mar. Sci. 89:551-557. Article

Howey, L. A., E. R. Tolentino, Y. P. Papastamatiou, E. J. Brooks,

D. L. Abercrombie, Y. Y. Watanabe, S. Williams, A. Brooks, D.

D. Chapman, and L. K. B. Jordan.

2016. Into the deep: the functionality of mesopelagic excursions by an oceanic apex predator. Ecol. Evol. 6:5290-5304. Article

Howey-Jordan, L. A., E. J. Brooks, D. L. Abercrombie, L. K. B. Jordan, A. Brooks, S. Williams, E. Gospodarczyk, and D. D. Chapman.

2013. Complex movements, philopatry and expanded depth range of a severely threatened pelagic shark, the oceanic whitetip (Carcharhinus longimanus) in the western North Atlantic. PLoS ONE 8(2):e56588. Article

Joung, S.-J., N.-F. Chen, H.-H. Hsu, and K.-M. Liu.

2016. Estimates of life history parameters of the oceanic whitetip shark, Carcharhinus longimanus, in the west- ern North Pacific Ocean. Mar. Biol. Res. 12:758-768. Article

Kalmijn, A. J.

1982. Electric and magnetic field detection in elasmobranch fishes. Science 218:916-918. Article

Lam, C. H., B. Galuardi, and M. E. Lutcavage.

2014. Movements and oceanographic associations of bigeye tuna (Thunnus obesus) in the northwest Atlantic. Can. J. Fish. Aquat. Sci. 71:1529-1543. Article

Li, W., X. Dai, Q. Xu, F. Wu, C. Gao, and Y. Zhang.

2016. The complete mitochondrial genome sequence of oceanic whitetip shark, Carcharhinus longimanus (Carcharhiniformes: Carcharhinidae). Mitochondrial DNA Part A 27:1775-1776. Article

Madigan, D. J., E. J. Brooks, M. E. Bond, J. Gelsleichter, L. A. Howey, D. L. Abercrombie, A. Brooks, and D. D. Chapman.

2015. Diet shift and site-fidelity of oceanic whitetip sharks Carcharhinus longimanus along the Great Bahama Bank. Mar. Ecol. Prog. Ser. 529:185-197. Article

Merten, W., R. Appeldoorn., R. Rivera, and D. Hammond.

2014. Diel vertical movements of adult male dolphinfish (Coryphaena hippurus) in the western central Atlantic as determined by use of pop-up satellite archival transmitters. Mar. Biol. 161:1823-1834. Article

Musyl, M. K., R. W. Brill, C. H. Boggs, D. S. Curran, T. K. Kazama, and M. P. Seki.

2003. Vertical movements of bigeye tuna (Thunnus obesus) associated with islands, buoys, and seamounts near the main Hawaiian Islands from archival tagging data. Fish. Oceanogr. 12:152-169. Article

Musyl, M. K., R. W. Brill, D. S. Curran, N. M. Fragoso, L. M. McNaughton, A. Nielsen, B. S. Kikkawa, and C. D. Moyes.

2011. Postrelease survival, vertical and horizontal movements, and thermal habitats of five species of pelagic sharks in the central Pacific Ocean. Fish. Bull. 109:341-368.

Neill, W. H., E. D. Stevens,, F. G. Carey, K. D. Lawson, N. Mrosovsky, and W. Frair.

1974. Thermal inertia versus thermoregulation in "warm" turtles and tunas. Science 184:1008-1010. Article

Neill, W. H., R. K. C. Chang, and A. E. Dizon.

1976. Magnitude and ecological implications of thermal inertia in skipjack tuna, Katsuwoaus pelamis (Lionreus). Environ. Biol. Fish.1:61-80. Article

Nelson, D. R., J. N. McKibben, W. R. Strong Jr., C. G. Lowe, J. A. Sisneros, D. M. Schroeder, and R. J. Lavenberg.

1997. An acoustic tracking of a megamouth shark, Megachasma pelagios: a crepuscular vertical migrator. Environ. Biol. Fish. 49:389-399. Article

Oliver, S., M. Braccini, S. J. Newman, and E. S. Harvey.

2015. Global patterns in the bycatch of sharks and rays. Mar. Policy 54:86-97. Article

Pade, N. G., N. Queiroz, N. E. Humphries, M. J. Witt, C. S. Jones, L. R. Noble, and D. W. Sims.

2009. First results from satellite-linked archival tagging of porbeagle shark, Lamna nasus: area fidelity, widerscale movements and plasticity in diel depth changes. J. Exp. Mar. Bio. Ecol. 370:64-74. Article

Pikitch, E. K., C. Santora, E. A. Babcock, A. Bakun, R. Bonfil, D. O. Conover, P. Dayton, P. Doukakis, D. Fluharty, B. Heneman, et al.

2004. Ecosystem-based fishery management. Science 305:346-347. Article 
Piovano, S., and E. Gilman.

2016. Elasmobranch captures in the Fijian pelagic longline fishery. Aquat. Conserv. Article

Queiroz, N., N. E. Humphries, L. R. Noble, A. M. Santos, and D. W. Sims.

2012. Spatial dynamics and expanded vertical niche of blue sharks in oceanographic fronts reveal habitat targets for conservation. PLoS ONE 7(2):e32374. Article

$\mathrm{R}$ Core Team.

2014. R: a language and environment for statistical computing. R Foundation for Statistical Computing, Vienna, Austria. [Available from website, accessed November 2014.]

Sepulveda, C. A., S. Kohin, C. Chan, R. Vetter, and J. B. Graham.

2004. Movement patterns, depth preferences, and stomach temperatures of free-swimming juvenile mako sharks, Isurus oxyrinchus, in the Southern California Bight. Mar. Biol. 145:191-199. Article

Shepard, E. L. C., M. Z. Ahmed, E. J. Southall, M. J. Witt, J. D. Metcalfe, D. W. Sims.

2006. Diel and tidal rhythms in diving behaviour of pelagic sharks identified by signal processing of archival tagging data. Mar. Ecol. Prog. Ser. 328:205-213. Article

Sims, D. W.

2003. Tractable models for testing theories about natural strategies: foraging behaviour and habitat selection of free-ranging sharks. J. Fish Biol. 63:53-73. Article

Sims, D. W., E. J. Southall, G. A. Tarling, and J. D. Metcalfe.

2005. Habitat-specific normal and reverse diel vertical migration in the plankton-feeding basking shark. J. Anim. Ecol. 74:755-761. Article

Speed, C. W., M. G. Meekan, I. C. Field, C. R. McMahon, and C. J. A. Bradshaw.

2012. Heat-seeking sharks: support for behavioural thermoregulation in reef sharks. Mar. Ecol. Prog. Ser. 463:231-245. Article

Tambourgi, M. R. D. S., F. H. V. Hazin, P. G. V. Oliveira, R. Coelho, G. Burgess, and P. C. G. Roque.

2013. Reproductive aspects of the oceanic whitetip shark, Carcharhinus longimanus (Elasmobranchii: Carcharhinidae), in the equatorial and southwestern Atlantic Ocean. Braz. J. Oceanogr. 61:161-168. Article

Tolotti, M. T., P. Travassos, F. L. Frédou, C. Wor, H. A. Andrade, and F. Hazin.

2013. Size, distribution and catch rates of the oceanic whitetip shark caught by the Brazilian tuna longline fleet. Fish. Res. 143:136-142. Article
Tolotti, M. T., J. D. Filmalter, P. Bach, P. Travassos, B. Seret, and L. Dagorn.

2015a. Banning is not enough: the complexities of oceanic shark management by tuna regional fisheries management organizations. Global Ecol. Conserv. 4:1-7. Article

Tolotti, M. T., P. Bach, F, Hazin, P. Travassos, and L. Dagorn. 2015b. Vulnerability of the oceanic whitetip shark to pelagic ongline fisheries. PLoS ONE 10(10):e0141396. Article

Tyminski, J. P., R. de la Parra-Venegas, J. González Cano, and R. E. Hueter.

2015. Vertical movements and patterns in diving behavior of whale sharks as revealed by pop-up satellite tags in the eastern Gulf of Mexico. PLoS ONE 10(11):e0142156. Article

Urmy, S. S., J. K. Horne, and D. H. Barbee.

2012. Measuring the vertical distributional variability of pelagic fauna in Monterey Bay. ICES J. Mar. Sci. 69:184-196. Article

Vianna, G. M. S., M. G. Meekan, J. J. Meeuwig, and C. W. Speed.

2013. Environmental influences on patterns of vertical movement and site fidelity of grey reef sharks (Carcharhinus amblyrhynchos) at aggregation sites. PLoS ONE 8(4):e60331. Article

Walker, M. M., T. E. Dennis, and J. L. Kirschvink.

2002. The magnetic sense and its use in long-distance navigation by animals. Curr. Opin. Neurobiol. 12:735-744. Article

Willis, J., J. Phillips, R. Muheim, F. J. Diego-Rasilla, and A. J. Hobday.

2009. Spike dives of juvenile southern bluefin tuna (Thunnus maccoyii): a navigational role? Behav. Ecol. Sociobiol. 64:57-68. Article

Wilson, S. G., J. J. Polovina, B. S. Stewart, and M. G. Meekan. 2006. Movements of whale sharks (Rhincodon typus) tagged at Ningaloo Reef, Western Australia. Mar. Biol. 148:1157-1166. Article

Wood, S. N.

2006. Generalized additive models: an introduction with R, 410 p. CRC Press, Boca Raton, FL.

World of Earth Science.

2003. Solar illumination: seasonal and diurnal patterns. Encyclopedia.com. [Available from website, accessed January 2016.]

Zagaglia, C. R., J. A. Lorenzzetti, and J. L. Stech.

2004. Remote sensing data and longline catches of yellowfin tuna (Thunnus albacares) in the equatorial Atlantic. Remote Sens. Environ. 93:267-281. Article 